\title{
Developing the GEA Method - Design Science and Case-Study Research in Action ${ }^{\star}$
}

\author{
Roel Wagter ${ }^{1,4}$, Henderik A. Proper ${ }^{2,4}$, and Dirk Witte ${ }^{3,4}$ \\ 1 PMTD, Rotterdam, The Netherlands \\ 2 CRP Henri Tudor, Luxembourg \\ 3 Logica, Amstelveen, The Netherlands \\ 4 Radboud University Nijmegen, Nijmegen, The Netherlands \\ roel.wagter@pmtd.nl, erik.proper@tudor.lu, dirk.witte@logica.com
}

\begin{abstract}
This paper is concerned with the research methodology that was used in the GEA (General Enterprise Architecting) research programme. The goal of this programme was the development of a new approach for doing enterprise architecture. We discuss the motivations for starting the GEA programme, its focus, as well as its objectives. Based on this, the research methodology as it was used by the GEA programme is discussed and motivated. This involves a combination of design science and case study based research. The paper also discusses the way the GEA programme went about to actually implement the research methodology in a real-world situation, while also highlighting its results.
\end{abstract}

Keywords: Enterprise architecture, enterprise coherence, design science.

\section{Introduction}

This paper focuses on the research methodology used in the GEA (General Enterprise Architecting) research programme. The goal of this programme was the development of a new approach to enterprise architecture. The scientific results of this programme have been reported in $[9,17,18,19,20,21,22]$. The focus of this paper is not on a discussion of these results, but rather on the way the programme was structured, the research methodology used, and the way it was actually implemented in practise.

In Section 2 we will briefly discuss the motivations for the GEA programme, its focus, and its objectives. This provides us with the context to discuss, in Section 3 , the research methodology used. Section 4 , then reports on the way this was actually implemented during the execution of the GEA programme. Finally, before concluding, Section 5highlights the results of the research programme.

\section{The GEA Research Programme}

The GEA method was developed in a multi-client research programme involving twenty organizations: ABN-AMRO Bank; ANWB (Dutch Automobile Club); Achmea

\footnotetext{
* This work has been partially sponsored by the Fonds National de la Recherche Luxembourg (www.fnr.lu), via the PEARL and CORE programmes.
}

X. Franch and P. Soffer (Eds.): CAiSE 2013 Workshops, LNBIP 148, pp. 43-57, 2013.

(C) Springer-Verlag Berlin Heidelberg 2013 
Insurances; Belastingdienst - Centrum voor ICT (IT department of the Dutch Tax Authority); ICTU (IT expertise centre of the Dutch government); ING Bank; Kappa Holding; Ministerie van Binnenlandse Zaken en Koninkrijksrelaties (Ministry of Foreign Affairs); Ministerie van Defensie (Ministry of Defence); Ministerie van Veiligheid \& Justitie - Dienst Justitiële Inrichtingen (Ministry of Public Safety and Justice); Ministerie van Landbouw, Natuur en Voedselkwaliteit (Ministry of Agriculture, Nature and Food quality); Nederlandse Spoorwegen (Dutch Railways); PGGM Pension Fund; Politie Nederland (Dutch Police); Prorail; Provincie Flevoland; RaboBank; Rijkswaterstaat (Executive agency of the Dutch Ministry of Infrastructure and the Environment); UWV (Agency for work \& social well-fare); Wehkamp.

The development of GEA was initiated in 2007 by the consultancy firm Ordina. The core driver for them to initiate the GEA programme [13] was their observation that in their experience enterprise transformations (changing an enterprise from its business processes to its underlying IT) fail more often than not. They also observed how existing methods and frameworks for enterprise architecture fell short in contributing to the success of enterprise transformation efforts [9, 13].

These experiences were also supported by a study conducted by the (Dutch) General Court of Auditors on the causes of failures of IT projects in the public sector in the Netherlands [1]. The resulting report [1] also links the failure of these projects to a lack of coherence/alignment between core aspects of the involved government agencies (translated from Dutch):

"ICT projects for the government seem to be much more expensive than anticipated initially, require more time than planned to complete, or do not deliver the desired results. This is a serious matter, since ICT projects of the government mostly involve the spending of public money. Furthermore the effects of projects that fail, to a larger or lesser extent, are often large-scale projects with profound social impact.

The most important cause of the (partial) failure of ICT projects revealed by the first part of the research was that ICT projects for the government are often overly ambitious and too complex because of the combination of politics, organizational and technical factors. With these overly complex projects there is no balance between ambition, available people, resources and time."

A survey [13] held at the start of the GEA research programme showed that these experiences were also shared among the client organizations participating in the programme. The underlying issues were considered grave enough for these organizations to indeed co-invest, in terms of time and money, in the GEA research programme. For the involved organizations, the important triggers were:

- many enterprise transformation efforts fail,

- failing to adopt a holistic approach to address key business issues, frequently leading to a unilateral approach from an IT oriented perspective,

- existing architecture methods fall short in meeting their promises because:

- they are set up from an IT perspective only,

- they hardly address the strategic level of the organization,

- they are set up in terms of the Business/IT gap and

- their underlying IT architectures applied on the enterprise-wide level are unjustly called enterprise architectures. 
The aforementioned survey [13] was also used to the requirements on the outcomes of the research programme. This also resulted in the formulation of the driving postulate of the programme: the overall performance of an enterprise is positively influenced by a proper coherence among the key aspects of the enterprise, including business processes, organizational culture, product portfolio, human resources, information systems, IT support, etc. The GEA programme refers to the latter coherence as enterprise coherence [13]. Enterprise coherence subsumes the traditional notion of 'Business-IT alignment' in the sense that it is not just 'business' and 'IT' that need to be aligned [17].

The above mentioned triggers were discussed in a workshop with a customer reference group of the client organizations involved in the GEA programme [13], leading to the formulation of the following problem definition: Many organizations lack enterprise coherence governance, where enterprise coherence was defined as follows [18]: "Enterprise coherence is the extent to which all relevant aspects of an enterprise are connected, in such a way that these connections facilitate an enterprise obtaining/meeting its desired results". Based on this five key research questions were formulated:

1. What are the core factors that define enterprise coherence?

2. What are the core factors that influence enterprise coherence?

3. What impacts does the governance of enterprise coherence have on the performance of enterprises in practise?

4. How can enterprise coherence be expressed explicitly?

5. How can enterprise coherence be governed?

More specifically, the research objectives of the research programme were:

1. Definition of the core indicators and factors that define enterprise coherence.

2. Definition of the core indicators and factors that influence enterprise coherence.

3. Identification of the potential impact factors of enterprise coherence governance on the organizational performance.

4. Be able to measure an enterprise's level of coherence governance.

5. A design theory on how to guard/improve the level of coherence in enterprises.

The latter design theory is referred to as the GEA method.

\section{Research Methodology}

\subsection{Design Science as the Basic Approach}

In developing the GEA method, the GEA programme used the Design Science research methodology. Design science addresses research through the building and evaluation of artefacts designed to meet the identified business need [4]. Design science research can be characterized as prescriptive research because it focuses on using existing knowledge to improve the performance of systems [6]. Thus, artefacts resulting from Design Science research are geared towards addressing business or organizational needs in a problem domain [4], or offering opportunities of improving practise even before practitioners identify any problem with their way of working [5]. Figure 1] shows how the Design Science approach has been applied in the GEA programme. 
The box on the left-hand side of Figure 1 represents the problem domain of the research programme, i.e. the environment of enterprise coherence governance consisting of organizations in the public and industrial area with more than 200 employees, a high degree of multiple forms of labour division, the business issues that influence the level of coherence and the people involved in enterprise coherence governance.

The boxes in the middle of Figure 1 represent the two major phases of the research programme, i.e. the develop/build phase and the evaluation phase of the intended theory and artefacts (i.e. GEA). The box on the right-hand side of Figure 1 shows examples of the theories, frameworks, instruments, constructs, models, techniques, measures and validation criteria that were adopted to develop GEA, so that it supports the execution of enterprise coherence governance. The Figure also shows that the GEA theory/method actually consists of three components (artefacts in design science terminology): ECA (Enterprise Coherence-governance Assessment) [17, 22], ECF (Enterprise Coherence Framework) [18] and ECG (Enterprise Coherence Governance-approach) [19, 23].

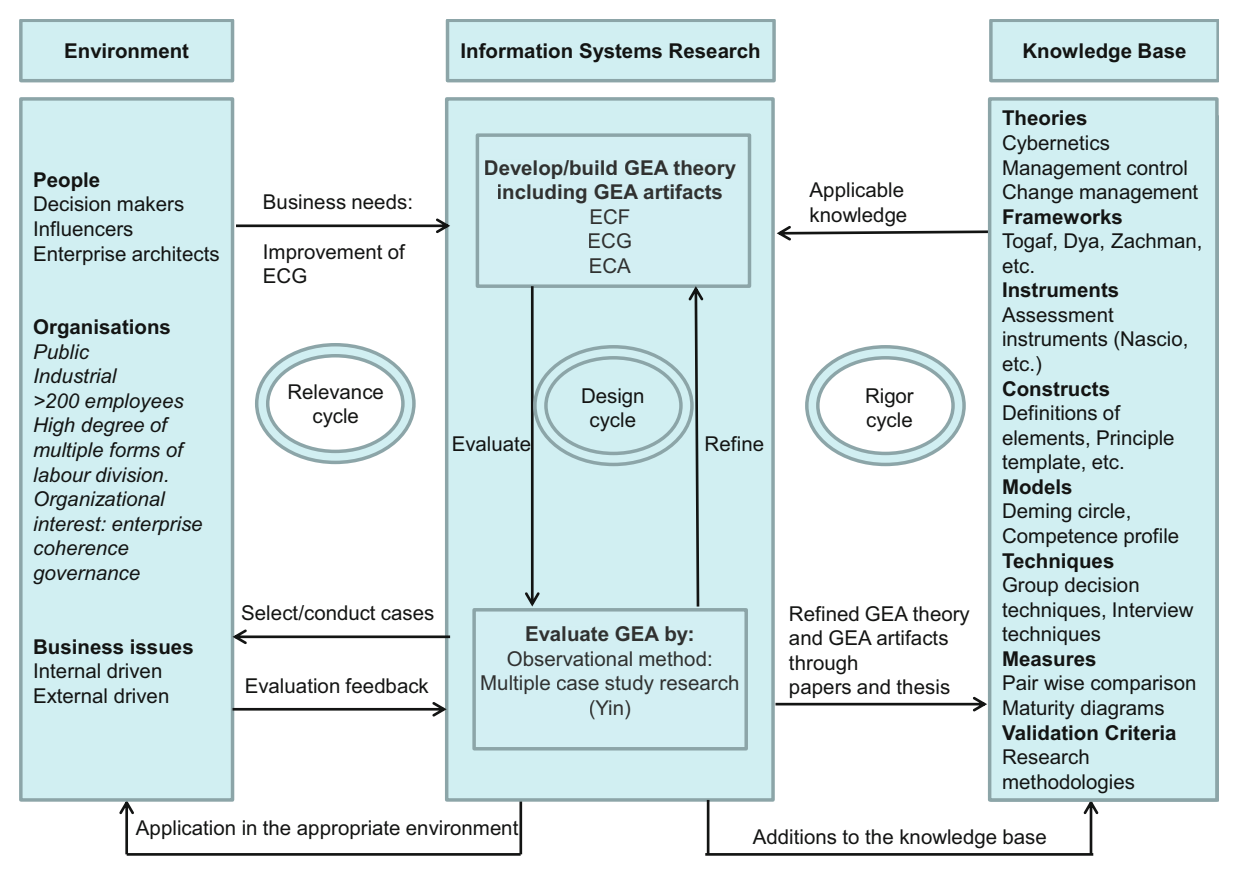

Fig. 1. Adoption of Design Science approach by the GEA programme [3, 4]

\subsection{Adoption of Design Science Research Guidelines}

Hevner et al [4] provide seven guidelines for proper Design Science research. Below we highlight how the GEA programme has endeavoured to meet these guidelines. 
Guideline 1: Design as an Artefact. Design science research must produce a viable artefact in the form of a construct, a model, a method, or an instantiation [4].

The key artefact resulting from the research programme is the GEA method, consisting of a theory and the artefacts ECF, ECG and ECA.

Guideline 2: Problem Relevance. The objective of Design Science research is to develop 'technology-based solutions' to important and relevant business problems [4]. The problem environment mainly comprises the level of purpose and the level of design of organizations, the business issues that influence the coherence at and between these levels and the people involved in enterprise coherence governance. The people involved in enterprise coherence governance are decision makers, influencers and enterprise architects. Design Science research is initiated by the identification and representation of challenging phenomena in the problem domain [3].

As shown in the left part of Figure 1 the challenge addressed in the GEA research programme is the improvement of enterprise coherence governance.

Guideline 3: Design Evaluation. The utility, quality, and efficacy of a design artefact must be rigourously demonstrated via well-executed evaluation methods. Evaluation of an artefact can be done using empirical and qualitative research methods such as observational, analytical, experimental, testing or descriptive-oriented methods [4].

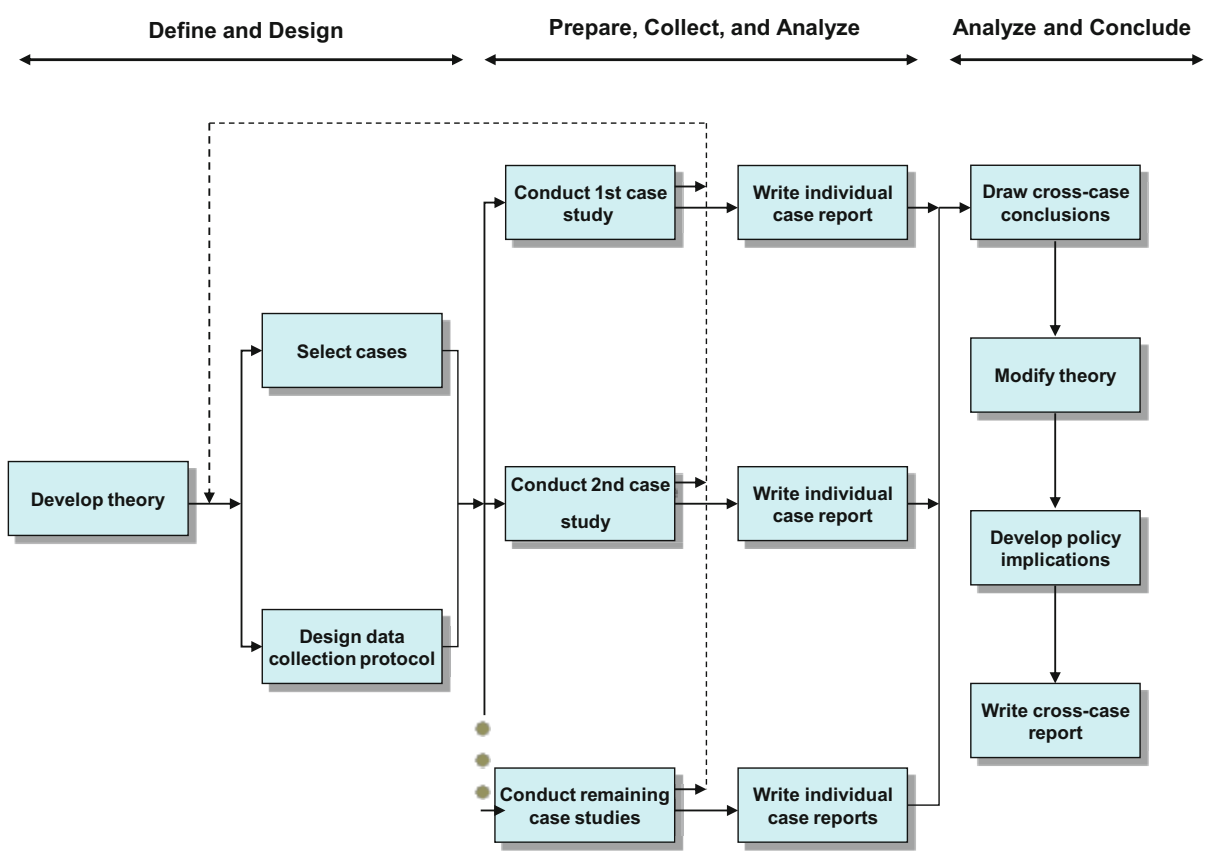

Fig. 2. Multiple case study research approach, adopted from Yin [32] 
The lower box in the middle part of Figure 1 shows the evaluation method used in the programme, being the multiple case study research approach from Yin [32] as illustrated in Figure 2.

Guideline 4: Research Contributions. Effective Design Science research must provide clear and verifiable contributions in the areas of the design artefact, design foundations, and/or design methodologies [4].

The lower middle part of Figure 1 shows that the main contribution of the research programme to the knowledge base consist of the GEA theory and its artefacts ECA, ECF and ECG as well as the publications reporting on its effect in practise.

Guideline 5: Research Rigour. Design Science research relies upon the application of rigourous methods in both the construction and evaluation of the design artefact. Design Science artefacts are created based on existing foundations and methodologies in a knowledge base which include theories, frameworks, instruments, constructs, models, methods, instantiations, experiences, and expertise [4].

The right part of Figure 1 shows the foundations and methodologies (i.e. existing literature) that we adopted in the development of GEA. The bottom of the left part of Figure 3 shows that existing literature and experiences was be applied in the design, evaluation, and modifying phases of the research programme.

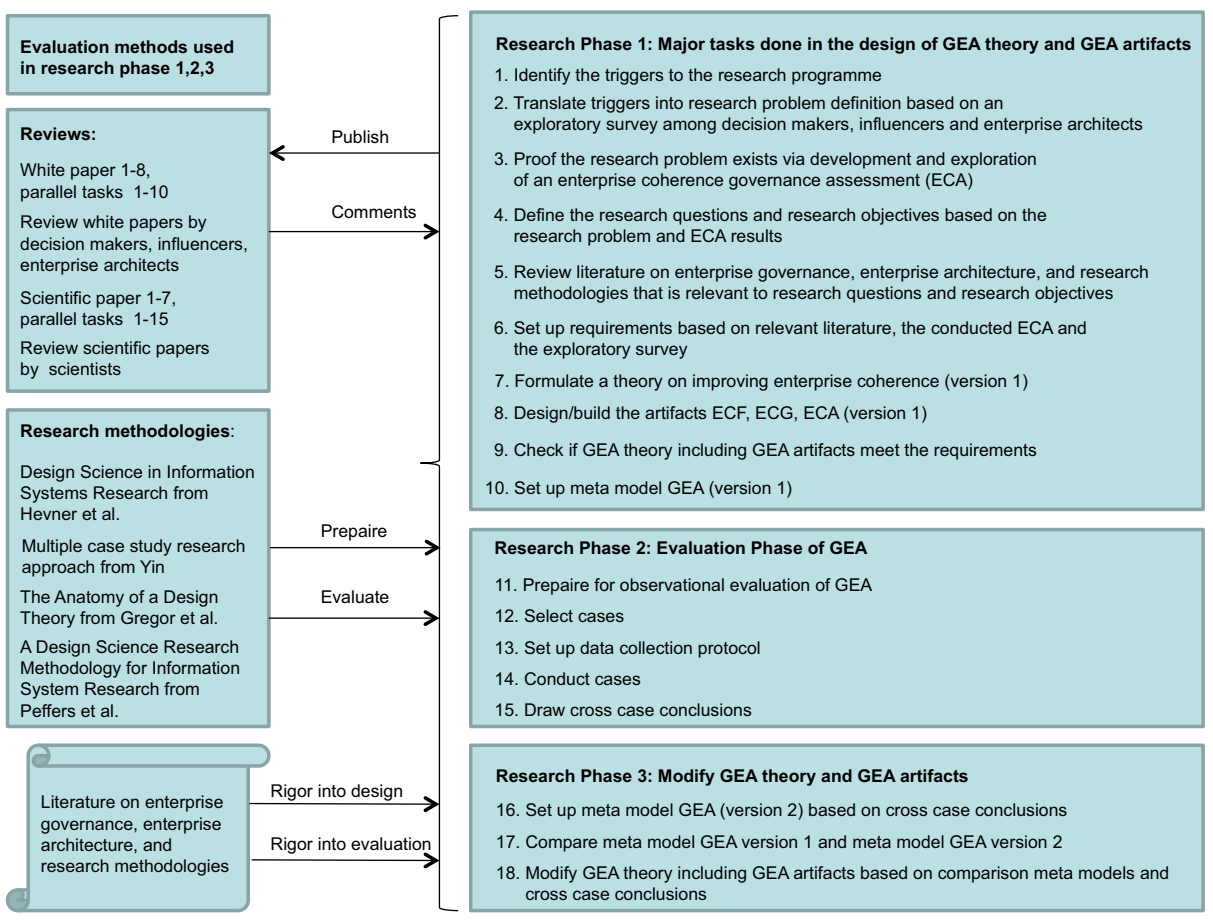

Fig. 3. Activities conducted to achieve the research objectives 
Guideline 6: Design as a Search Process. The search for an effective artefact requires utilizing available means to reach desired ends while satisfying laws in the problem environment [4]. Design involves iterative research activities such as constructing, evaluating, and refining the artefact based on findings [3].

The major design activities to carry out in the research programme to achieve the research objectives are shown in the right part of Figure 3 It also shows that all the development activities to conduct in the research programme have been grouped into phase 1 , phase 2 and phase 3 . The result of phase 1 consist of the first version of GEA and the evaluation phase 2 formed the basis to modify GEA during phase 3 into the final version of GEA. In the left part of Figure 3 the evaluation methods that were used in the research programme are shown.

While using the Design Science approach from Hevner et al. [3, 4] as the overal research approach, the GEA programme also used:

- The Multiple Case Study Research Approach by Yin [32] to conduct phase 2.

- The Anatomy of a Design Theory by Gregor et al. [2] was used to evaluate GEA.

- The Design Science Research Methodology for Information System Research by Peffers et al. [7] was used as a 'template' for the GEA design process.

- In order to develop the initial versions of several of the GEA artefacts the group decision technique MetaPlan [8] was used.

Note: When the GEA programme was initiated in 2007, some of these approaches were not yet available [2, 7]. However, soon after their publication, these approaches were indeed integrated in the planning of the GEA programme as shown in Figure 3.

Guideline 7: Communication of Research. Design Science research must be presented effectively both to technology-oriented as well as management-oriented audiences. Communication of the research programme was targeted both at academic and industrial audiences, more specifically leading to several scientific publications [17, 18, $19,20,21,22,23,24]$ and industrial publications $[9,10,11,12,13,14,15,16,25$, 26, 27, 28, 29, 30, 31]. The latter class of publications also played an important role in ensuring the relevance of the research results, as well as in ensuring a continued access to relevant case studies. This also made it necessary to target these publications at the local Dutch speaking EA community.

\subsection{Research Activities of the GEA Programme}

In fulfilling the above guidelines, the GEA programme followed the relevance, rigour, and design cycles as identified by Hevner et al [3], and in particular the design research process as suggested by Peffers et al. [7]. This process is illustrated in Figure 4

The resulting process as followed by the GEA programme was already illustrated in Figure 3 The relevance, rigour, and design cycles that are typical of design science, are present throughout the listed research activities. For example, the relevance cycle is represented by tasks $2,3,11,12,13,14,15$. The rigour cycle is represented by the adoption and application of existing scientific literature. The design cycle is represented in Figure 3 by the activities in tasks 1-4, 6-10 and 16-18. 


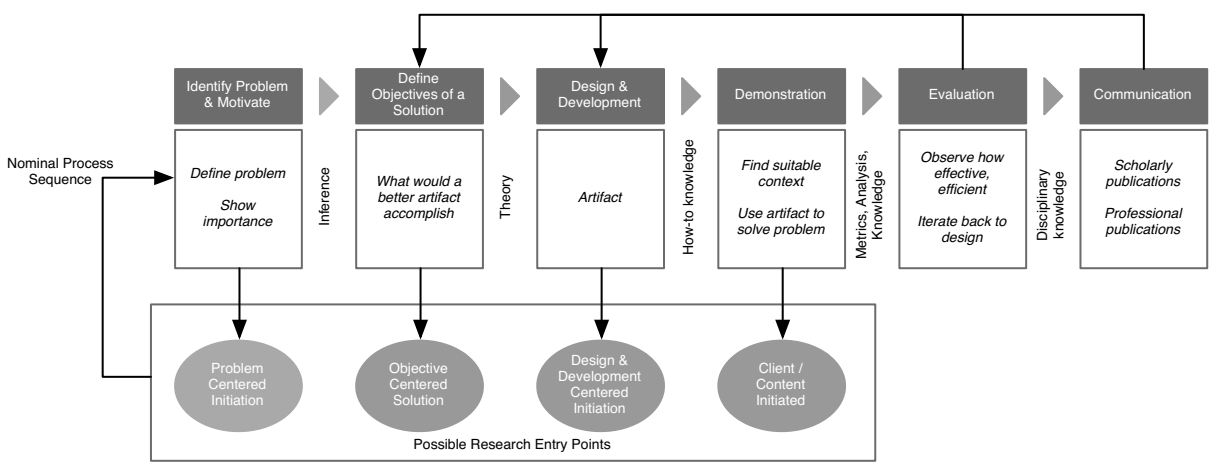

Fig. 4. Design research [7]

\section{Implementation of the GEA Programme}

\subsection{Setup of the Research Programme}

The GEA research programme itself was structured in terms of four groups:

1. A core team consisting of six to eight people with in-depth knowledge in the field of enterprise architecture.

2. A customer reference group representing the twenty major enterprises who cofinanced the programme. These representatives involved policy makers, managers of enterprise architecture departments and lead enterprise architects.

3. An expert review team involving thirty lead enterprise architects.

4. A steering committee with seven leading representatives from science and industry.

To participate in one of these groups, candidate participants had to meet strict criteria:

1. For the core team, the participants were required to have in-depth knowledge of the field of enterprise architecture and a willingness to spent a considerable amount of time on the activities of the research programme.

2. For the customer reference group, participants were required:

- to be working in one of the participating client organizations,

- have a strong affinity with the discipline of enterprise architecture,

- identify with the triggers and research problem of this research,

- to be willing to discuss the interim results of this research on a regular basis and

- to be willing (as an organization) to co-fund the research effort.

3. To be part of the expert review team, members were required to have an in-depth knowledge in the field of enterprise architecture and the willingness to thoroughly evaluate the interim results of this research within a relatively short time-span.

4. The scientific members of the steering committee were required to be among the leaders in their field. The industrial members of the steering committee were required to be employed/working at the boardroom level. All members of the steering committee were required to have the willingness (and commitment) to discuss the innovation strategy of this research on a regular basis. 
The (potential) interests for the participants to be involved in this study were:

1. For the members of the core team it was an opportunity to follow their deep passion for the field of enterprise architecture, and be part of an effort to improve the field.

2. For the members of the customer reference group, participation provided a way to acquire better instruments to resolve enterprise coherence problems in practise.

3. For the members of the expert review team it was the opportunity to enrich their knowledge in the field of enterprise architecture with cutting edge insights.

4. For the scientific members of the steering committee it provided a way to obtain closer contact with relevant parties in industry. For the industrial members of the steering committee it provided a way to obtain better governance instruments.

The actual involvement (and composition) of these groups depended on the specific phase of the research programme. The results of the research activities, as conducted by the core team, were regularly discussed with (and evaluated by) the customer reference group. The members of the expert review team were charged with the responsibility to guard the quality by thoroughly evaluation the results. The steering committee regularly assessed the progress of the programme and the development strategy followed.

\subsection{Development Process}

As one of the first activities, the ECA (Enterprise Coherence-governance Assessment) instrument was developed and used in seven organizations to assess their level of enterprise coherence. The primary aim of the exercise was to assess if the perceived problem (Many organizations lack enterprise coherence governance) actually manifested itself in practise. Furthermore, jointly with the partners who co-invested in the research programme, a go/no-go criterion was formulated: if more than $50 \%$ of the seven organizations involved in the first ECA studies lack enterprise coherence governance, it was safe to assume that the lack of enterprise coherence governance is indeed a relevant issue that needs further elaboration by the GEA programme.

The secondary goal for the development of the ECA, and its application in seven participating organizations, was to gain an initial insight into research question number one and three: What are the core factors that define enterprise coherence? What impacts does the governance of enterprise coherence have on the performance of enterprises in practice? On the one hand, the answer to these questions provided insight into the need to carry out further research into the governance of enterprise coherence, while on the other hand providing a first refined definition of enterprise coherence and its practical impact on organizational performance.

At the start of the GEA research programme, the intention was to actually conduct three of such ECA studies during the programme:

1. A first assessment at the start of the programme, providing a baseline measure.

2. A second assessment once a shared understanding of enterprise coherence was reached. By comparing the results to the baseline, the effect of having a shared awareness of the forces that influence coherence should be measurable.

3. A final assessment once proper/full governance of enterprise coherence would be put in place in a participating organization. By comparing these final assessment 
results to the earlier ones, the additional effect of coherence governance could be made explicit.

Nevertheless, soon after the start of the research programme, it became apparent that doing these three assessments was not feasible. In the time needed for such longitudinal assessments, the composition of the involved organizations, as well as the people involved, would change so much that the results would no longer be comparable between the first, second and third moment of measuring. It was therefore decided to integrate the ECA into the GEA method, and use the ECA in each of the cases in which GEA would be applied, and use its outcomes to drive the research activities in phase 2 (see Figure 3, in particular using Yin's [32] case based approach.

\subsection{Case Studies}

During phase 2 (see Figure 3), the GEA theory (or parts thereof) was applied in multiple organizations with the goal to evaluate the theory, and make improvements where needed. More specific goals for the case studies were: Does the GEA theory meet its requirements?, Are the artefacts as defined by GEA producible in practise?, and Is GEA effective and applicable as a governance instrument?

In selecting the case studies, the focus was on large organizations involving a broad application of the GEA results. The primary case studies included:

- Professionalization in administrative body of a ministry of the Dutch goverment [23].

- An impact assessment of the introduction of a new law at the Custodial Institutions Agency of the Dutch Ministry of Public Safety and Justice [24].

- Digitization of the document flow at a ministry of the Dutch government [20, 21].

In line with Yin [32], the case studies involved the use of an explicit data collection protocol. Yin suggests to use five levels of questions in collecting data:

1. Questions to specific interviewees.

2. Questions at the level of an individual case (these are the questions in the case study protocol to be answered by the investigator during a single case, even when the single case is part of a larger, multiple-case study).

3. Questions focused on finding patterns across multiple cases.

4. Questions at the level of the entire research effort (for example, calling on information beyond the case study evidence and including literature or published data that may have been reviewed).

5. Normative questions about policy recommendations and conclusions, going beyond the narrow scope of the study.

The specific questions are, for each level, given below. These questions were validated by the core team of the GEA programme.

\section{Level 1:}

- At the time of the validation process of the ECF:

1. Are the guiding statements valid and up to date? 
2. Do the representatives of the perspectives agree with the identified perspectives, the identified core concepts within it and the related guiding statements?

- At the time of the ECG analysis process of a major business issue:

1. Do the causes, triggers, sub problems, risks, implications, etc. of the business issue lead to change initiatives?

2. Do the (existing) guiding statements result in additional change initiatives or restrictions (the so called solution space)?

\section{Level 2:}

- Are the documents at the level of purpose present and accessible?

- Does the definition of the level or purpose result in a clear understanding of the sense of purpose and design of the organization?

- Is one able to identify, and engage, the right representatives for each of the perspectives? This engagement should cover both the identification and validation of the cohesive GEA elements and the analysis processes to solve the business issue.

- Are the representatives of the perspectives able to validate the ECF?

- Are the representatives of the perspectives, using the validated ECF, able to execute the analysis processes to solve major business issues?

- Does the development of the ECF lead to an increase of enterprise coherence?

- Does the use of GEA lead to an integral solution that contributes to the coherence of the organization?

- Is the organization able to, autonomously, specify a business issue that can serve as input to a GEA based analysis?

- Do the owners of the business issue succeed in specifying the business issue in such a way the representatives of the prospects can perform the complete GEA analysis and develop an integral solution?

\section{Level 3:}

- The level 3 questions about the pattern of findings across multiple cases are:

1. Degree of acceptance by stakeholders?

2. Extend of applicability?

3. Extend of matching required dynamics?

4. Extend of compliance with required integrality?

5. Degree of accessibility?

6. Degree of transferability?

7. Extend of balance of interests?

8. Degree of innovativeness?

\section{Level 4:}

- Did the execution of the cases result into detectable performance improvements?

- Does the literature support the answers to the above findings? 


\section{Level 5:}

- What recommendations can be made towards the further development and expansion of the area of enterprise coherence?

The data gathering, structuring and analysis resulted in the validation of evaluation criteria such as: degree of acceptance by stakeholders, extend of applicability, achieved level of coherence governance, degree of transferability, balance between interests of different stakeholders, and level of innovation.

\section{Results of the GEA Programme}

The core result of the GEA programme is the GEA method, being a (situational) design theory on how to achieve enterprise coherence, involving three main components: ECA (Enterprise Coherence-governance Assessment) [17, 22], ECF (Enterprise Coherence Framework) [18] and ECG (Enterprise Coherence Governance-approach) [19, 23].

Scientific results of the GEA programme have been published in several papers [17, 18, 19, 20, 21, 22, 23, 24], while results have been communicated to practitioners as well in terms of white papers and industry oriented publications $[9,10,11,12,13,14$, $15,16,25,26,27,28,29,30,31$.

Collectively, the GEA method components cover the GEA concepts as depicted in Figure 5, where one concept builds on the other, leading to a coherent whole. All the promises of the EA-Vision, such as improving the coherence of the organization, should be achieved through the execution of EA-Processes. The execution of the EA-Processes results in EA-Products that will direct change programmes and via this the enterprise coherence. EA-People are needed to carry out the EA-Processes and to produce the EAProducts. EA-People needs, to execute the EA-Processes, sufficient allocation of means in terms of time, budgets and tools. EA-People and the execution of EA-Processes need to be governed by EA-Governance. And finally to store a maintainable formal description of the formulation of the EA-Vision, EA-Processes, EA-Products, EA-People and EA-Governance there is a need for an EA-Methodology. The ECG binds all these concepts together in a workable procedure for doing enterprise architecture.

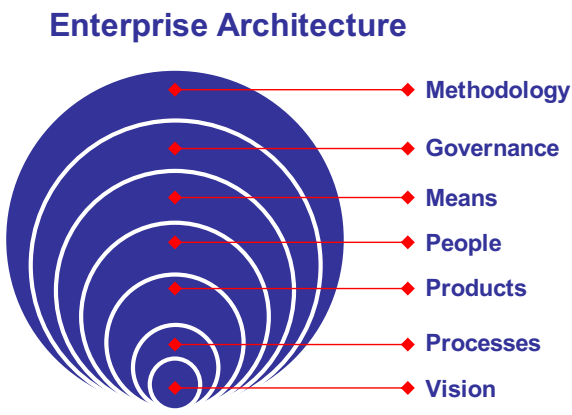

Fig. 5. Coherent set of GEA concepts 
Using the criteria from Gregor et al. [2], the results can be summarized as follows.

Purpose and Scope. The purpose and scope of the GEA method is the development of an approach for understanding, governing and improving enterprise coherence

Constructs. The constructs the GEA method consists predominantly of the ECF, which makes an enterprise's coherence explicit, an ECG to govern and to improve the enterprise coherence, and an ECA to measure the level of enterprise coherence governance.

Principle of Form and Function. The GEA method is a methodology to aid in the identification of the level of enterprise coherence and issues a set of processes and heuristics to measure and improve the enterprise coherence governance.

Artefact Mutability. Suggestions for improving the GEA method are given for further work and research: one example is further research in applying the GEA method in cases of strategic alliances.

Testable Propositions. It is claimed that the GEA method is adaptable to situational settings, despite of its positioning as a general approach.

Justificatory Knowledge. The GEA method is derived from other governance theories and enterprise architecture approaches and based on several design theories.

Principles of Implementation. It is stated that implementation of the GEA method requires facilitation by a facilitator experienced in enterprise architecture, governance approaches, assessment approaches and running collaborative workshops.

Expository Instantiation. Three key examples of the application of the GEA method are given in large real world cases.

\section{Conclusion}

In this paper we discussed the research methodology used in the GEA (General Enterprise Architecting) research programme. The goal of this multi-client (involving twenty organizations) research programme was the development of a new approach for doing enterprise architecture. We discussed the motivations for starting the GEA programme, its focus, as well as the objectives. Based on this, the research methodology used by the GEA programme was discussed. This involved a combination of design science research and case study based research. We also elaborated on the way the GEA programme went about to actually implement the research methodology in a real-world situation, while also highlighting the results of the programme. The programme was structured around four groups of participants: a core team, a customer reference group, an expert review team and a steering committee. In the course of the programme, intermediate results were published. Not only targeted at an academic audience, put specifically also at an industrial audience to ensure continued support (in the market) for the GEA method during its development.

The most important lesson learned of applying the chosen research methodologies is the assurance of a high quality of the GEA method in terms of being relevant, rigour, proper evaluated and proper designed. 


\section{References}

1. Lessen uit ICT-projecten bij de overheid, Deel B. De Algemene Rekenkamer (2008) (in Dutch)

2. Gregor, S., Jones, D.: The anatomy of a design theory. Journal of the Association for Information Systems 8(5), 312-335 (2007)

3. Hevner, A.R.: A Three Cycle View of Design Science Research. Scandinavian Journal of Information Systems 19(2), 87-92 (2007)

4. Hevner, A.R., March, S.T., Park, J., Ram, S.: Design Science in Information Systems Research. MIS Quarterly 28, 75-106 (2004)

5. Iivari, J.: A Paradigmatic Analysis of IS as a Design Science. Scandinavian Journal of Information Systems 19(2), 39-64 (2007)

6. March, S.T., Smith, G.F.: Design and natural science research on information technology. Decision Support Systems 15(4), 251-266 (1995)

7. Peffers, K., Tuunanen, T., Rothenberger, M.A., Chatterjee, S.: A design science research methodology for information systems research. Journal of Management Information Systems 24(3), 45-77 (2007)

8. Schnelle, E.: Neue Wege der Kommunikation. Spielregeln, Arbeitstechniken und Anwendungsfälle der Metaplan-Methode. Number Heft 10. Hanstein, Königstein/Taunus, Germany (1978) (in German)

9. Wagter, R.: Sturen op samenhang op basis van GEA - Permanent en event driven. Van Haren Publishing, Zaltbommel (2009) (in Dutch)

10. Wagter, R., Mahakema, M., Stovers, R., Krijgsman, W., Witte, D.: TOGAF en GEA: een gouden koppel? TIEM (44) (Maart 2012) (in Dutch)

11. Wagter, R., Nijkamp, G., Proper, H.A.: Applying GEA to a business issue. White Paper GEA-5, Ordina, Utrecht, The Netherlands (2007) (in Dutch)

12. Wagter, R., Nijkamp, G., Proper, H.A.: GEA-Benchmark: Measuring cohesion. White Paper GEA-3, Ordina, Utrecht, The Netherlands (2007) (in Dutch)

13. Wagter, R., Nijkamp, G., Proper, H.A.: Overview 1th Phase - General Enterprise Architecturing. White Paper GEA-1, Ordina, Utrecht, The Netherlands (2007) (in Dutch)

14. Wagter, R., Nijkamp, G., Proper, H.A.: The Elements of the "GEA-Structure". White Paper GEA-2, Ordina, Utrecht, The Netherlands (2007) (in Dutch)

15. Wagter, R., Nijkamp, G., Stovers, R., Proper, H.A.: E-Government using GEA and NORA. White Paper GEA-4, Ordina, Utrecht, The Netherlands (2007) (in Dutch)

16. Wagter, R., Nijkamp, G., Witte, D., Proper, H.A.: GEA in relation to other steering instruments. White Paper GEA-8, Ordina, Utrecht, The Netherlands (2008) (in Dutch)

17. Wagter, R., Proper, H.A., Witte, D.: Enterprise Coherence Assessment. In: Harmsen, F., Grahlmann, K., Proper, E. (eds.) PRET 2011. LNBIP, vol. 89, pp. 28-52. Springer, Heidelberg (2011)

18. Wagter, R., Proper, H.A., Witte, D.: Practice-Based Framework for Enterprise Coherence. In: Proper, E., Gaaloul, K., Harmsen, F., Wrycza, S. (eds.) PRET 2012. LNBIP, vol. 120, pp. 77-95. Springer, Heidelberg (2012)

19. Wagter, R., Proper, H.A., Witte, D.: Enterprise Architecture: A strategic specialism. In: Rinderle-Ma, S., Sanz, J., Bai, X.-Y. (eds.) Proceedings of the 14th IEEE Conference on Commerce and Enterprise Computing (CEC 2012), pp. 1-8. IEEE Computer Society, Hangzhou (2012)

20. Wagter, R., Proper, H.A., Witte, D.: Enterprise Coherence in the Dutch Ministry of Social Affairs and Employment. In: Bajec, M., Eder, J. (eds.) CAiSE 2012 Workshops. LNBIP, vol. 112, pp. 600-607. Springer, Heidelberg (2012) 
21. Wagter, R., Proper, H.A., Witte, D.: On the Use of GEA at the Dutch Ministry of Social Affairs and Employment. In: Rinderle-Ma, S., Sanz, J., Bai, X.-Y. (eds.) Proceedings of the 14th IEEE Conference on Commerce and Enterprise Computing (CEC 2012), pp. 115-119. IEEE Computer Society, Hangzhou (2012)

22. Wagter, R., Proper, H.A., Witte, D.: The Extended Enterprise Coherence-governance Assessment. In: Aier, S., Ekstedt, M., Matthes, F., Proper, E., Sanz, J.L. (eds.) PRET 2012 and TEAR 2012. LNBIP, vol. 131, pp. 218-235. Springer, Heidelberg (2012)

23. Wagter, R., Proper, H.A., Witte, D.: A theory for Enterprise Coherence Governance. In: Saha, P. (ed.) A Systemic Perspective to Managing Complexity with EA. IGI Publishing (to appear, 2013)

24. Wagter, R., Proper, H.A., Witte, D.: Enterprise Coherence Governance in the Public Sector. In: Submitted to CBI 2013, 15th IEEE Conference on Business Informatics (2013)

25. Wagter, R., Stovers, R., Nijkamp, G., Proper, H.A.: GEA-processes and products, a closer examination. White Paper GEA-6, Ordina, Utrecht, The Netherlands (2007) (in Dutch)

26. Wagter, R., Witte, D.: GEA in relation to other steering instruments. White Paper GEA-8 (May 2008) (in Dutch)

27. Wagter, R., Witte, D.: Strategische stuurinstrumenten vergeleken. TIEM (33) (October 2009) (in Dutch)

28. Wagter, R., Witte, D.: Sturen op samenhang op basis van GEA. XR-magazine (May 2010) (in Dutch)

29. Wagter, R., Witte, D.: Toepassing van het strategische stuurinstrument GEA. TIEM (35) (February 2010) (in Dutch)

30. Wagter, R., Witte, D., Goutier, H., Lieshout, J.: NORA 3.0 als stuurinstrument op basis van GEA. TIEM (39) (November 2010) (in Dutch)

31. Wagter, R., Witte, D., Proper, H.A.: The GEA architecture function: A strategic specialism. White Paper GEA-7, Ordina, Utrecht, The Netherlands (2007) (in Dutch)

32. Yin, R.K.: Case Study Research - Design and Methods, 4th edn. Sage Publications (2009) 